\title{
Rapsódia em agosto
}

\author{
SERGIO LEITÃO ${ }^{I}$
}

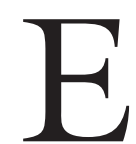

M UM FILME de 1991, intitulado Rapsódia em agosto, o diretor de cinema japonês Akira Kurosawa retrata a vida de Kane, uma anciã que vive em Nagasaki, a segunda cidade japonesa a ser alvo da explosão de uma bomba atômica, ocorrida em 9 de agosto de 1945, no final da Segunda Guerra Mundial, setenta anos atrás (a primeira bomba caiu sobre Hiroshima em 6 de agosto).

O filme se passa durante as férias de verão, quando Kane, que perdeu o marido na explosão da bomba, cuida dos seus quatros netos e ainda recebe a visita de um sobrinho americano, vivido pelo ator Richard Gere. O diretor japonês, então, se serve da história de Kane para fazer uma poderosa análise do holocausto nuclear e de seus efeitos sobre a sociedade japonesa.

Numa das cenas mais tocantes do filme, Kane e seus netos, ao visitarem o memorial dedicado à lembrança da explosão na cidade, deparam com um espelho d'água onde estão esculpidos em pedra os rostos dos que ali morreram. As crianças leem uma placa dizendo que um dos efeitos mais perversos da detonação da bomba nuclear em Nagasaki foi matar de sede suas vítimas, numa agonia lenta, torturante. Ato contínuo, os netos de Kane se atiram para dentro do espelho d'água e começam, com as suas mãos, freneticamente, a atirar água sobre os rostos entalhados na pedra, num gesto simbólico de aplacar a sede e o sofrimento daqueles que morreram de forma tão dolorosa.

A cena descrita leva-nos a perguntar se o infortúnio dos moradores das cidades de Hiroshima e Nagasaki (onde morreram mais de 240 mil pessoas) ensinou algo de definitivo à humanidade, demonstrando o poder fatal das armas nucleares, o que continuaria a justificar o seu banimento da face da Terra?

Ou será que o poder do átomo, espalhado pelos mais variados usos, como na medicina e na energia, estabeleceu-se de forma tão onipotente que fez o drama do seu emprego na guerra ganhar o aspecto de mero efeito colateral, apenas indesejável, diante de vastos e amplos benefícios?

E afinal, em que medida as discussões acima repercutem no Brasil, já que o mundo não foi o mesmo depois de agosto de 1945?

Este texto vai procurar discutir algumas dessas perguntas à luz da evolução do debate sobre o uso da energia nuclear no Brasil e no mundo.

\section{A ciência e o poder do átomo no Brasil}

No período que vai dos anos 30 até 60 do século XX, a capacitação em ciência e tecnologia no país esteve originariamente ligada ao tema da energia nuclear, sendo imperioso reconhecer os esforços que a união entre militares e 
cientistas legou para a pesquisa nacional, capitaneados pelo almirante Álvaro Alberto, cujo fruto mais substancioso foi a criação do CNPq (Conselho Nacional de Pesquisa Científica e Tecnológica).

Físico, químico, militar e um dos fundadores da Academia Brasileira de Ciências, Álvaro Alberto foi designado, em 1946, representante do Brasil na recém-criada Comissão de Energia Atômica das Organizações das Nações Unidas (ONU), justamente com o objetivo de fazer o controle, em escala mundial, do uso da energia nuclear.

Resultado direto da explosão das bombas no Japão, ao mundo se impunha a questão sobre o controle daquele poderio assombroso, que colocava em risco a sobrevivência da própria humanidade. Daí a outorga dessa competência à ONU, que ensaiava os seus primeiros passos como organismo incumbido de plasmar as instituições e regras que estabeleceriam a nova ordem mundial, a ser edificada sobre os escombros da Segunda Guerra.

Como afirmou o físico dinamarquês Niels Bohr (cujas pesquisas nucleares contribuíram decisivamente para a criação da era atômica), em texto publicado em 11 de agosto de 1945, poucos dias após as explosões atômicas no Japão: “é óbvio, entretanto, que nenhum tipo de controle será eficaz sem o livre acesso à totalidade das informações científicas e sem a possibilidade de supervisão internacional de todos os empreendimentos que, salvo se regulamentados, poderiam se converter numa fonte de catástrofe".

O problema é que a supervisão internacional exigia, como afirmou Bohr, "a abolição das barreiras até hoje vistas como necessárias para a salvaguarda dos interesses nacionais, mas que agora se converteram em obstáculos à segurança comum contra perigos sem precedentes".

Este ainda continua a ser o principal problema no controle das atividades nucleares, já que vários países, alegando suas prerrogativas de soberania, se recusam a aderir aos tratados internacionais que regem o assunto, como o Tratado de Não Proliferação de Armas Nucleares (TNP). Ao mesmo tempo, e não sem alguma razão, alegam que os mecanismos de controle da ONU não são inteiramente democráticos, servindo muito mais como uma espécie de cláusula de barreira, que mantém a tecnologia nuclear acessível apenas a um clube restrito, criando claros desequilíbrios na balança de poder mundial.

A presença de Álvaro Alberto na ONU aguçou a sua percepção de que a Segunda Guerra Mundial deixou como resultado inelutável o "progresso da física nuclear e do consequente aproveitamento industrial da nova energia", alicerçada em sua visão de que a guerra "se tornou a maior força propulsora dos avanços da ciência e da tecnologia".

É a percepção e a visão de Álvaro Alberto que o impelem a defender a criação do CNPq quando do seu retorno ao Brasil, em junho de 1948. No início de 1949, por designação do então presidente Eurico Gaspar Dutra, ele preside a comissão de 22 cientistas formada para elaborar o projeto propondo a criação do 
órgão, que só veio a ser aprovado pelo Congresso Nacional em janeiro de 1951, já no último mês do mandato de Dutra.

Ao $\mathrm{CNPq}$ competia, entre outras funções, o controle das atividades nucleares, cabendo-lhe adotar "as medidas de incentivo às pesquisas nessa área e em todas as demais indispensáveis ao futuro aproveitamento industrial da nova energia".

Para Álvaro Alberto, evocando sua formação militar, os esforços de fazer pesquisa no Brasil reclamavam "a instituição de um estado-maior da ciência, da técnica e da indústria, que lhes trace seguros rumos e lhes fomente e coordene as atividades". Ele justificava sua visão com o que havia acontecido durante a Primeira Guerra Mundial, quando países como Inglaterra, Canadá e Estados Unidos da América estabeleceram os seus conselhos nacionais de pesquisa, com o objetivo de fazer uso da "ciência e da técnica como base de sua produção econômica", o que só se intensificou durante a Segunda Guerra.

A despeito de o CNPq em seus albores não se ocupar apenas da questão atômica, para Álvaro Alberto é clara a centralidade do tema dentro do novo órgão, "cuja significação não é excedida pela de qualquer outro problema técnico-industrial concernente ao futuro da nacionalidade, no concerto dos países soberanos".

Em que pese o entendimento do almirante Álvaro Alberto, a verdade é que, de lá para cá, a energia nuclear não se constituiu no único eixo propulsor da atenção governamental em relação à nossa capacitação tecnológica. De há muito a ciência no Brasil respira outros ares, possuindo o país 25 núcleos de excelência científica, espalhados por onze áreas do conhecimento, de acordo com estudo publicado na edição de dezembro de 2006 da revista Anais da Academia Brasileira de Ciências.

Contamos ainda com mais de sessenta mil cientistas e engenheiros de alto nível realizando atividades de pesquisa com competitividade internacional, como reconheceu o ex-ministro da Ciência e Tecnologia do governo Lula, Sergio Rezende (Folha de S.Paulo, p.A3, edição de 3.12.2006). Não bastasse, estamos entre os treze países que mais produzem artigos científicos no mundo, ocupando, por exemplo, o segundo lugar quando se trata de temas ligados à proteção da saúde animal.

A capacitação científica e tecnológica de quadros nacionais não depende mais da aposta única e exclusiva em bolsões de pesquisa separados da formulação de uma estratégia nacional e democrática de desenvolvimento, onde, além de uma estrutura de fomento, importa ao país aparelhar-se para participar da corrida global pela inovação, sem deixar de estimular que o investimento privado participe desse esforço.

Mas, apesar da nova realidade, ainda hoje o debate sobre a questão nuclear no Brasil recorre ao passado para alimentar a visão de que, se não construirmos novas usinas nucleares, como é o caso de Angra 3, estaremos jogando uma pá de 
cal na política de pesquisa e desenvolvimento tecnológico do país. E com isso, estaremos inviabilizando, por exemplo, o processo de aquisição da capacitação necessária para o uso da tecnologia nuclear nos campos da agricultura e da medicina.

O início da capacitação para o uso da tecnologia nuclear na agricultura brasileira, por exemplo, data dos anos 1960 (com a criação do Centro de Energia Nuclear na Agricultura da Universidade de São Paulo), quando não havíamos construído nenhuma das nossas usinas atômicas de energia (a primeira só começou a ser construída na década de 70 do século passado). E, se o argumento fosse mesmo verdade, países como Alemanha e Suíça não teriam decidido parar com a construção de novas usinas. Ou seja, não construir Angra 3, 4 ou 5 não impedirá que os nossos médicos salvem vidas com o uso da radioterapia ou que façamos o exame de tireoide em clínica com equipamentos mais sofisticados, pois para tanto o que precisamos é de reatores de pesquisa que permitam a produção de isótopos necessários ao diagnóstico e tratamento de câncer.

Hoje, compete à Comissão Nacional de Energia Nuclear (CNEN), e não mais ao CNPq, exercer o duplo papel de fiscalizar e fomentar o uso da energia nuclear. Isso, porém, não significa que tenhamos inovado substancialmente no desenho institucional dos nossos organismos da área nuclear. A concentração de papéis na CNEN contraria tratados internacionais que o país assinou, orientados pelo amplo entendimento de que os riscos associados ao uso da tecnologia atômica exigem a clara separação entre as funções de fomentar e de fiscalizar.

Tal burla dos dispositivos do direito internacional deixa o Brasil na amarga e insólita companhia do Irã e do Paquistão, únicos países onde isso ainda ocorre também. Repetir um padrão institucional adotado pelos dois deveria ser motivo de real preocupação para nós, dado o histórico de problemas daquelas nações com o controle das suas atividades nucleares.

\section{A bomba e o desequilíbrio de poder mundial}

As explosões das bombas atômicas em Hiroshima e Nagasaki mudaram a concepção da divisão de poder entre as nações de forma radical, alterando completamente o equilíbrio de forças em escala mundial. Quem não tinha o seu próprio estoque de armas nucleares estava claramente em desvantagem nos salões da diplomacia em que se decidiam os destinos do mundo (a clássica concepção de que a guerra é a continuação da diplomacia, ainda que por outros meios, também evanesceu, sendo possível afirmar que após o advento das armas atômicas é a diplomacia que se tornou a continuidade das guerras).

Não é à toa que os países que integram o Conselho de Segurança das Nações Unidas - Estados Unidos, Rússia, China, França e Reino Unido (os chamados membros permanentes, os vencedores da Segunda Guerra), com poder de veto sobre as decisões tomadas pela maioria das outras nações que integram a organização, têm como traço de comunhão o fato de cada um deles possuir armas atômicas. 
Armas que, na visão de Albert Einstein, agravaram ainda mais o perigo das guerras, em razão de um fator de natureza técnica: "os armamentos modernos, em particular a bomba atômica, fizeram com que os meios de ataque ganhassem vantagens consideráveis sobre os meios de defesa".

A opinião de Einstein é reforçada pela de Philip Morrison, participante do projeto de construção da primeira bomba atômica e que esteve no Japão investigando os efeitos da explosão em Hiroshima, o qual afirma ser o conceito de saturação o que caracteriza o desastre de uma cidade atingida por um artefato nuclear. E ele assim explica o conceito de saturação:

se você atacar um homem ou uma cidade, sua vítima irá se defender. Vai atacar de volta, usar fogo antiaéreo, apagar os incêndios, cuidar dos feridos, reconstruir as casas, jogar lonas sobre as máquinas deixadas ao relento. Quanto mais forte seu golpe, mais ela fará para se defender. Mas se você atacar de uma só vez com força esmagadora, ela será incapaz de se defender. Ficará atordoada. As baterias antiaéreas da cidade disparam a toda carga, os bombeiros estão ocupados apagando as chamas em suas próprias casas. Então, você poderá, impunemente, redobrar o ataque. A vítima já está fazendo tudo o que é possível, deixa de ser capaz de responder a mais ataques, intensificando os esforços de defesa. As defesas ficam saturadas.

Para Philip, a bomba atômica é, "antes de tudo, uma arma de saturação, que destrói de forma tão completa uma área tão grande que as defesas são destroçadas". Ele relata, para que possamos entender a razão da aplicação dessa conceituação, que em Hiroshima havia "33 quartéis do corpo de bombeiros", sendo que "vinte e sete deles foram inutilizados". E continua:

três quartos do pessoal de combate ao fogo foram mortos ou ficaram gravemente feridos. Ao mesmo tempo, centenas, talvez milhares de incêndios irromperam nas zonas arrasadas. Como controlar esses incêndios? Duzentos e cinquentas mil pessoas ficaram feridas em cerca de um minuto. O médico responsável pelo sistema de saúde pública foi soterrado sob sua casa. Seu assistente também morreu, assim como o assistente do assistente. $\mathrm{O}$ comandante das forças armadas foi morto, assim como seu ajudante e o ajudante do ajudante e, na verdade, todos os membros da sua equipe. Dos 298 médicos registrados, apenas trinta estavam em condições de cuidar dos sobreviventes. De um total de cerca de 2.400 enfermeiros e auxiliares de enfermagem, apenas seiscentos estavam prontos para o trabalho após a explosão. Como seria possível cuidar dos feridos e organizar a evacuação de forma correta? A subestação de energia elétrica que servia o centro da cidade fora destruída, a estrada de ferro interrompida e a estação ferroviária, arrasada e incendiada. As redes telefônicas e telegráficas, desmanteladas. Todos os hospitais da cidade, com a exceção de um, foram fortemente danificados, e nenhum deles era capaz de abrigar seus pacientes da chuva - mesmo que sua estrutura de concreto permanecesse de pé - sem telhado, paredes ou esquadrias. Áreas inteiras dos subúrbios permaneceram ilesas, mas seus habitantes não foram capazes de prestar ajuda eficaz, por lhes faltar liderança, organização, suprimentos e abrigos. 
E, segundo ainda o relato de Philip, "um funcionário do governo de Hiroshima, apontando para sua cidade arrasada, disse: tudo isso causado por uma única bomba. É insuportável”.

É a expressão de incredulidade acima transcrita, diante de um poder de destruição absolutamente desconhecido, o que pode explicar a corrida iniciada em 1945 pela posse de armas atômicas. Essa corrida nunca mais teve fim e, o que é pior, vem contando sempre com a adesão de novos corredores.

Apesar das análises que indicavam que uma guerra nuclear traria consequências tão nefastas que, nas palavras de Irving Langmuir, é possível que "algum dia venhamos a encarar a bomba atômica como a descoberta que possibilitou à humanidade pôr fim a todas as guerras", deu-se exatamente o contrário. O Clube Atômico é formado hoje por nove países que possuem armas nucleares: Estados Unidos, Rússia, China, Reino Unido, França, Israel (não reconhece que as tem), Índia, Paquistão e Coreia do Norte.

E isso se dá mesmo com a celebração, em julho de 1968, do TNP, do qual atualmente 190 países são signatários (Índia, Coreia do Norte e Paquistão não aderiram ao Tratado). Na verdade, o Tratado não conseguiu evitar o surgimento de outros países com armas atômicas, tampouco reduziu o número de ogivas nucleares existentes - em 1968 havia 39.429 ogivas no mundo e esse número atingiu o seu pico em 1986, com 69.368 ogivas.

O impulso para uma maior redução do número de armas atômicas veio dos acordos entre russos e americanos, assinados principalmente depois que a União Soviética já estava se esfarelando. Em 31 de julho de 1991, foi assinado o primeiro Acordo de Redução de Armas Estratégicas (START - Strategic Arms Reduction Treaty) entre Estados Unidos e União Soviética. Quando entrou em vigor, em 1994, a União Soviética já fazia parte apenas da história, mas o acordo foi aceito pela Rússia.

Após o START expirar em 2009, foi assinado o Novo START, em 2010, acordo que entrou em vigor em 5 de fevereiro de 2011. O acordo mantém e aprimora alguns aspectos do primeiro START, estabelecendo, porém, metas mais ambiciosas.

Em comparação com 2013, houve uma redução de mais de $9 \%$ no número de ogivas em todo o mundo. Essa diminuição decorre, principalmente, das reduções realizadas por Estados Unidos e Rússia em seus arsenais (mesmo assim, os dois países ainda possuem $89 \%$ das ogivas atômicas do mundo).

Isso, no entanto, esconde o fato de que a maioria dos membros do Clube Atômico segue modernizando seus arsenais nucleares, que continuam sendo fundamentais em suas estratégias de segurança nacional. Somente o custo do programa de manutenção e modernização dos sistemas de armas nucleares dos Estados Unidos foi estimado em US\$ 355 bilhões em uma década, o que certamente estimula gastos correspondentes por parte de Rússia e China. 


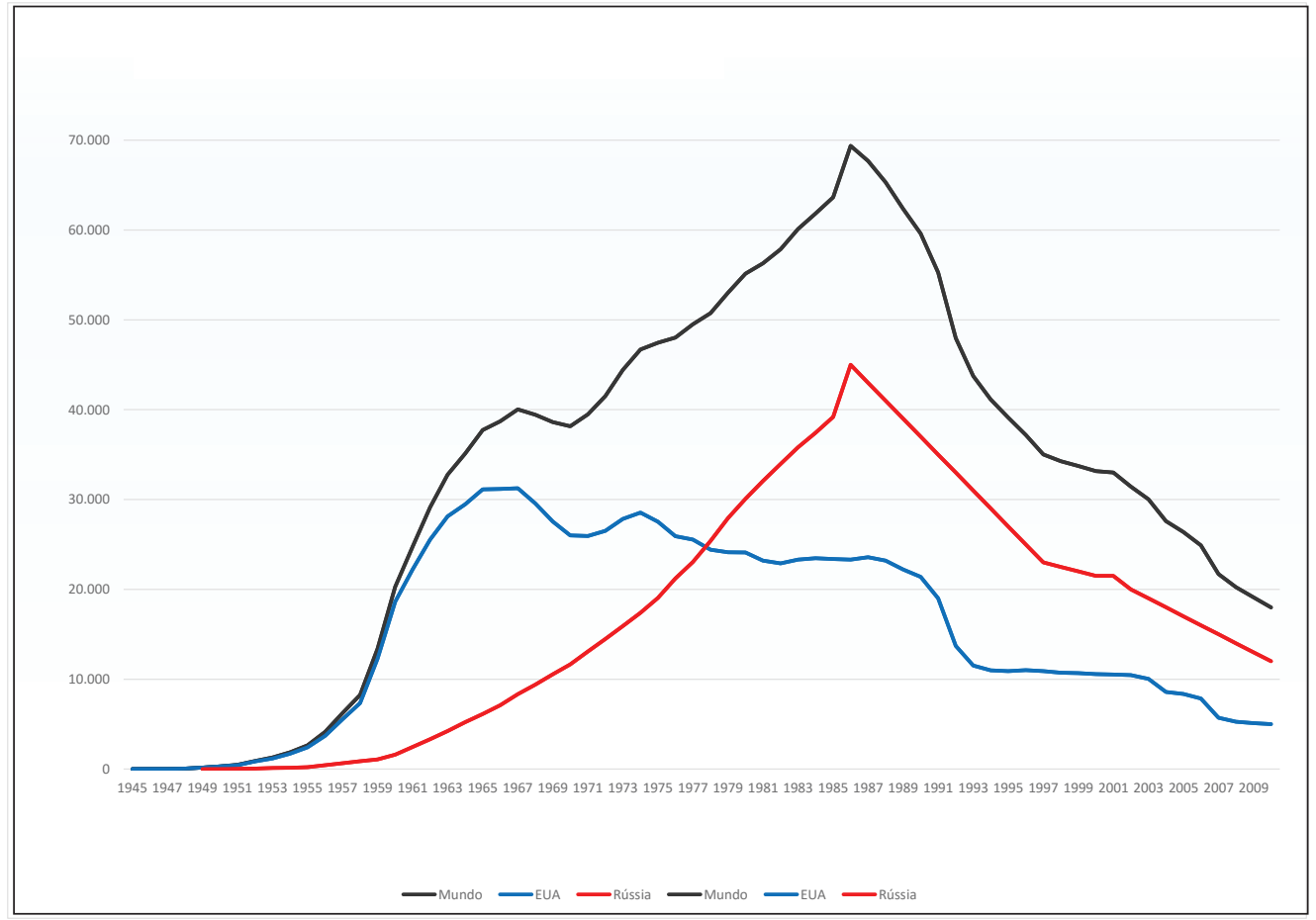

Fonte: Norris e Kristensen (2010).

Gráfico l - Número de ogivas nucleares 1945-2010.

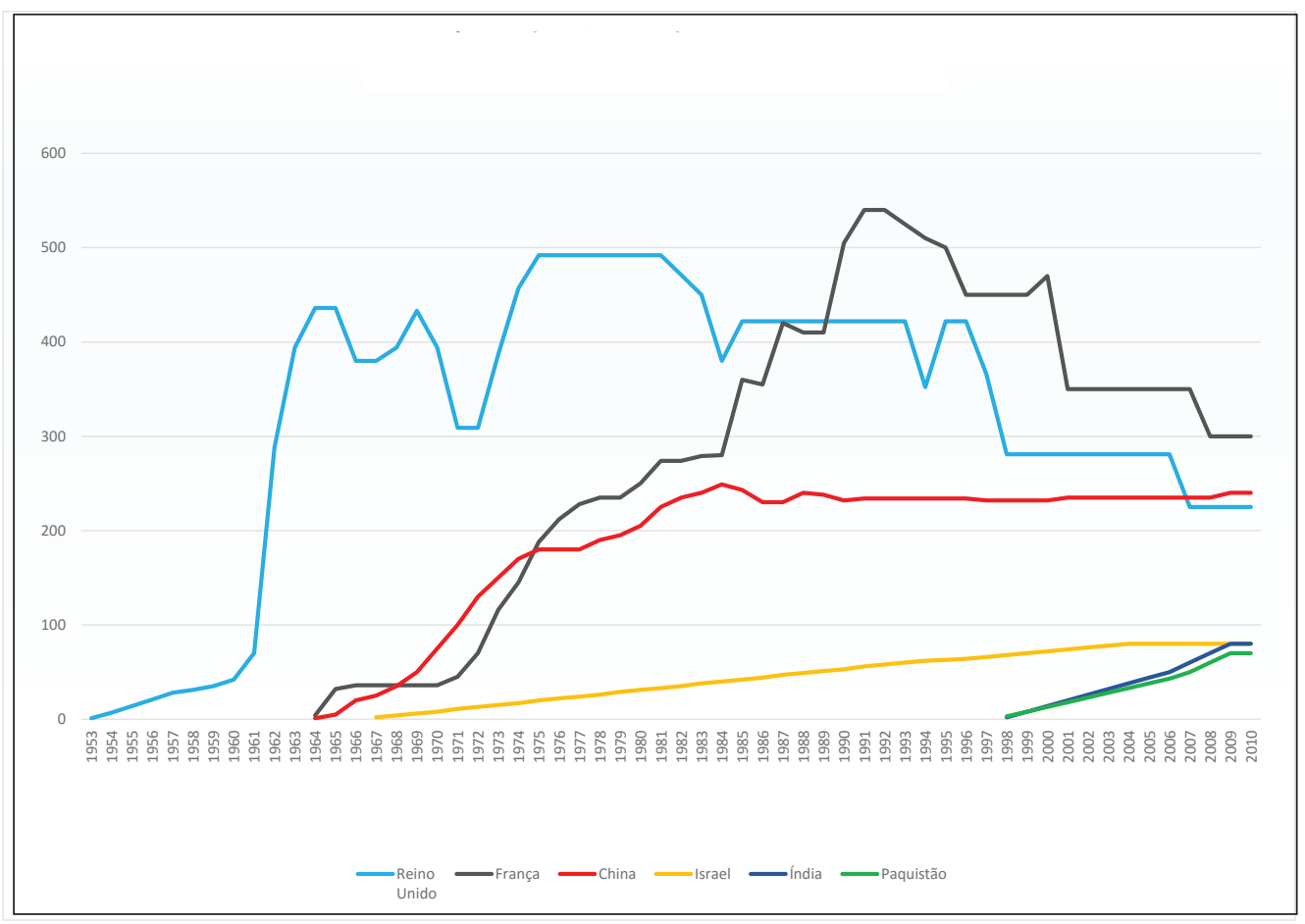

Fonte: Norris e Kristensen (2010).

Gráfico 2 - Número de ogivas nucleares 1953-2010. 
Com tudo isso, de acordo com o Stockholm International Peace Research Institute (Sipri), em maio de 2014 havia aproximadamente 16.300 ogivas nucleares no mundo, e 3.970 estão "operacionais" - armadas em mísseis ou presentes em bases militares com forças operativas, prontas para serem acionadas.

Mas, como desgraça pouca é bobagem, novas tensões geopolíticas tendem a induzir o crescimento das armas nucleares.

Ainda na década de 1980, a Arábia Saudita comprou da China mísseis balísticos com capacidade para carregar ogivas nucleares. O Irã, por sua vez, passa a ser acusado de implantar um programa nuclear que teria por objetivo final a construção da bomba. A possível aquisição de armas nucleares pela Arábia Saudita e Irã faria que outros países passassem a considerar a entrada no Clube Atômico, como Turquia e Egito (setores do Itamaraty advogam que a "solução duradoura para a questão reside na conclusão de um acordo que faça do Oriente Médio uma zona livre de armas nucleares").

Com o recente acordo nuclear entre Irã, Estados Unidos e Europa se consolidando, existe a ameaça de uma nova corrida por armas nucleares. Embora o acordo trate apenas de energia nuclear para uso civil, contraditoriamente, países como Israel e Arábia Saudita se opõem a ele, alegando que o Irã, que é signatário do TNP, não abriu mão do seu desejo não revelado de possuir a bomba.

Com isso, a Arábia Saudita passa a anunciar que, caso o Irã adquira esse poder, ela também o fará. E aqui vale lembrar que grande parte do programa nuclear paquistanês foi financiado justamente pela família Saud, dinastia reinante na Arábia Saudita. A Agência Central de Inteligência dos Estados Unidos (CIA) inclusive está hoje investigando se o Paquistão já entregou para a Arábia Saudita armas nucleares (Kaye in Internacional Business Times, 2015).

No caso da Coreia do Norte, que efetuou com sucesso seu primeiro teste nuclear em 2006, acredita-se que tenha hoje entre seis e oito ogivas nucleares. Em maio de 2015, o país anunciou ter lançado pela primeira vez um míssil balístico intercontinental (ICBM) de um submarino. Em seguida, anunciou ter desenvolvido a tecnologia para "miniaturizar" ogivas nucleares, o que permitiria armar mísseis balísticos com essas ogivas. Em outras palavras, caso os anúncios sejam verdadeiros, o país está perto de adquirir a capacidade de lançar mísseis nucleares a partir de submarinos.

Assim, se em 1986 havia 69.368 ogivas nucleares prontas para fazer o mundo virar um imenso cogumelo atômico, elas somam agora (saudemos!) apenas 16.300. Só que, a julgar pelos números e novas tendências, estamos longe de alcançar o desejo acalentado após o fim da Segunda Guerra de livrar o mundo do perigo da hecatombe nuclear. Tudo leva a crer que não aprendemos nada ou muito pouco com o sofrimento dos que morreram de sede em Hiroshima e Nagasaki. Nossos arsenais nucleares continuam saturados de armas de saturação.

E o problema cresce ainda mais quando surge o alerta de que não só não eliminamos as armas nucleares como, ao contrário, estamos aperfeiçoando-as, 
aprimorando-as. John Mecklin, em artigo na Revista Foreign Policy (março/ abril de 2015), fala da sua preocupação com o desenvolvimento de uma nova geração de armas nucleares, cada vez menores, mais precisas e com menor emissão de radiação - o que, nas suas palavras, só "aumenta a tentação em usá-las".

Para Mecklin, estamos ingressando em uma nova fase da corrida armamentista atômica, em que não interessa mais a quantidade de bombas no estoque, mas sim a sua capacidade de destruição, de precisão. Isso torna ainda mais distante o sonho do fim do pesadelo atômico e só evidencia que quem tem a bomba não demonstra a menor intenção de abrir mão do seu poderio. Os Estados Unidos, por exemplo, não aderiram ao Tratado de Proibição Completa dos Testes Nucleares, de 1996, que proíbe qualquer tipo de teste nuclear, assinado por 183 países.

No que se refere ao Brasil, essa perspectiva sombria em escala global apenas estimula a oposição que setores militares e da nossa diplomacia fazem ao fato do país ter aderido ao TNP. A adesão, que ocorreu no governo Fernando Henrique Cardoso (FHC) em 1998, com a devida ratificação do Tratado pelo Congresso, é vista por esses setores como parte da "herança maldita" da octaéride de FHC.

Até porque, o quadro acima descrito açula os ânimos dos que entendem que quem não tem armas nucleares não conta no jogo das grandes nações. Isso, apesar da proibição expressa contida no artigo 21 da Constituição de 1988 quanto à utilização da energia atômica para fins militares (oriunda de proposta do então senador Itamar Franco).

É sob o influxo do pensamento de que "se alguns podem, eu também tenho direito", que o Itamaraty contestou a adesão do Brasil ao Protocolo Adicional do TNP, já no governo Lula, escorado nas argumentações do seu então secretário geral, embaixador Samuel Pinheiro Guimarães (2005):

O Brasil não deve aceitar normas internacionais que contrariem ou criem empecilhos a seus interesses fundamentais de reduzir as desigualdades, de eliminar as vulnerabilidades e de realizar seu potencial... A reserva brasileira ou a ausência do Brasil de qualquer negociação não provocará nada de arrasador para o Brasil (como a recusa da Índia em aderir ao TNP demonstra cabalmente).

Importante perceber que a argumentação do embaixador Samuel não difere, ontologicamente, daquela apresentada pelo embaixador Araújo Castro, em 1968 (o presidente do país era o general Costa e Silva). Na época, o Brasil se opôs ao projeto do TNP, alegando que "entre os nucleares não há proibições", o que propicia que as potências que detêm a tecnologia das armas nucleares se conservem como tais, "até os fins dos tempos, já que o projeto de tratado parece ter sido concebido sob o signo da irreversibilidade". O embaixador Castro ainda arremata a sua argumentação dizendo que o sistema de controle desenhado pelo projeto do TNP "só atinge as potências não-nucleares" (o TNP permite que 
somente Estados Unidos, Rússia, China, França e Reino Unido tenham armas nucleares e proíbe que qualquer outro país que a ele aderiu as desenvolva).

Esse sentimento de exclusão que brota das manifestações da nossa diplomacia só foi reforçado pelo episódio frustrado da iniciativa do governo Lula de, em conjunto com a Turquia, tentar mediar um acordo sobre o programa nuclear do Irã. O ex-chanceler Celso Amorim diz que os interesses exclusivos dos países do Conselho de Segurança das Nações Unidas inviabilizaram a mediação brasileira, porque a arrogância de cada um deles, inclusive China e Rússia, prevaleceu "sobre os esforços pacifistas de dois outsiders". Para Amorim (2015), o fato se deu porque "o sistema político mundial ainda não foi capaz de absorver as mudanças [...] na geometria do poder. Mas isso ocorrerá fatalmente, ainda que [a espera] dure vinte ou trinta anos. E [quando ocorrer] será em benefício da paz no mundo".

Assim, em que pesem as mudanças de regime político, de governo, e a própria passagem do tempo que poderia ensejar revisões em concepções tão arraigadas, pode-se dizer que o apego ao poder nuclear como uma espécie de passaporte para uma modernidade técnico-industrial está mais vivo do que nunca.

Ecoando o que já dizia Álvaro Alberto há mais de cinquenta anos, quando das discussões sobre a criação do CNPq, a Estratégia Nacional de Defesa lançada pelo governo Lula em 2008, afirmava:

Projeto forte de defesa favorece projeto forte de desenvolvimento. Forte é o projeto de desenvolvimento que, sejam quais forem suas demais orientações, se guie pelos seguintes princípios: b) Independência nacional, alcançada pela capacitação tecnológica autônoma, inclusive nos estratégicos setores espacial, cibernético e nuclear. Não é independente quem não tem o domínio das tecnologias sensíveis, tanto para a defesa como para o desenvolvimento.

Ciência e tecnologia assumem, portanto, a responsabilidade de serem as linhas condutoras por onde trafega a construção dos projetos de desenvolvimento e defesa do país, o que deve se materializar pelo domínio de campos sensíveis do conhecimento, como é o caso do espacial, cibernético e nuclear, todos eles capazes de assegurar a nossa independência diante das demais nações do mundo.

Mas qual o limite que se coloca ao pleno domínio dessas tecnologias? E, como corolário inevitável da pergunta anterior, há que saber se o país está realmente convencido de que podemos ter um projeto de desenvolvimento e de defesa sem que seja necessário trazer na cintura uma cartucheira recheada de armas atômicas.

Como vimos antes, a proibição do emprego da energia atômica para fins militares está longe de ser um assunto resolvido, ou, como diriam os juristas, uma "cláusula pétrea da nossa Constituição"; isto é, dispositivo que não admite revisão. Não custa lembrar que foi no governo do ex-presidente Collor de Mello, em 1990, dois anos após a entrada em vigor do novo texto constitucio- 
nal, que se deu o desmantelamento do chamado Programa Nuclear Paralelo, que mantinha instalação no Campo de Provas de Cachimbo, no Pará, destinada ao teste de uma bomba nuclear.

\section{Conclusão}

No Japão há uma palavra, Hibakusha, que designa aqueles que foram afetados pelas explosões das bombas em Hiroshima e Nagasaki. De certo modo, pode-se afirmar que os efeitos daqueles artefatos atômicos se fizeram incidir sobre todo o mundo, influenciando decisivamente os jogos de poder entre as nações, as estratégias da guerra, e alterando radicalmente o modo como as pessoas percebiam o mundo em que viviam - tudo simplesmente poderia desaparecer de uma hora para outra em decorrência de uma conflagração entre potências nucleares.

Então, podemos afirmar que as gerações de 45 para cá, em todos os países, de certo modo, simbolicamente são Hibakusha, vítimas da bomba, porque suas vidas passaram a lidar com a possibilidade de que os fatos acontecidos no Japão há setenta anos voltassem a se repetir, com consequências ainda mais trágicas.

Embora seja verdade que em alguns momentos o mundo esteve bem próximo de um conflito, como no caso da crise da instalação dos mísseis nucleares em Cuba, em 1962, houve também períodos em que o problema parecia controlado, quase irrelevante, como com o fim das tensões da guerra fria em razão da queda do Império Soviético.

Aliado a isso, o fato de os conflitos tradicionais não darem trégua aos nossos olhos cansados de tanto horror exibido pela televisão, um se sucedendo ao outro, fez que o tema do banimento das armas nucleares fosse perdendo a prioridade que tinha até o fim dos anos 1970, até mesmo na Europa.

Mas, infelizmente, os dados sobre a contínua expansão e modernização do aparato nuclear indicam a necessidade de os cidadãos em todo o mundo prestarem atenção ao problema novamente. O perigo está mais perto do que nunca, com os seus efeitos perversos podendo se disseminar em escala global.

A condição de Hibakusha, afinal, é o elo entre todas as pessoas do mundo potencialmente ameaçadas por uma explosão atômica, que fariam parte daquilo que Beck chama de uma "comunidade de perigo" por estarem submetidas aos mesmos riscos, em sua dimensão catastrófica de "autodestruição de toda a vida sobre a Terra".

E é dessa condição que pode surgir o sentido de uma crítica cidadã que estabeleça os claros limites ao poderio técnico da energia atômica, como fez recentemente o povo alemão ao exigir o fim da construção de novas usinas nucleares no país.

Que a passagem dos setenta anos da tragédia atômica no Japão sirva para a retomada do debate sobre o desarmamento nuclear em todos os países do mundo, sem exceções. Essa é a melhor forma de honrar a memória dos que morreram. 
Referências

AMORIM, C. Teerã, Ramalá e Doha: memórias da política externa ativa e altiva. São Paulo: Benvirá, 2015

ARCHER, R. Energia atômica, soberania e desenvolvimento. Rio de Janeiro: Contraponto, 2006.

BOHR, N. Prólogo: ciência e civilização. In: Um mundo ou nenhum: Relatório ao público sobre o pleno significado da bomba atômica. São Paulo: Paz e Terra, 2008. BRASIL. Decreto n.2.864, de 7 de dezembro de 1998. Disponível em: <http://www.planalto.gov.br/ccivil_03/decreto/d2864.htm>. Acessado em: 20 maio 2015.

EINSTEIN, A. A saída. In: . Um mundo ou nenhum: Relatório ao público sobre o pleno significado da bomba atômica. São Paulo: Paz e Terra, 2008.

ELETRONUCLEAR. Panorama da Energia Nuclear no Mundo. Edição Novembro 2011. Disponível em: <http://www.eletronuclear.gov.br/LinkClick.aspx?fileticket=Gx Tb5TAen5E\%3D\&tabid=297>. Acessado em: 19 maio 2015.

FAS - FEDERATION OF AMERICAN SCIENTISTS. Status of World Nuclear Forces. Disponível em: <http://fas.org/issues/nuclear-weapons/status-world-nuclear-forces/>. Acesso em: 22 maio 2015.

GADDIS, J. L. História da Guerra Fria. Rio de Janeiro: Nova Fronteira, 2006.

GARCIA, J. C. V. Álvaro Alberto: a ciência do Brasil. Rio de Janeiro: Contraponto, 2000 .

Nuclear - A energia polêmica, mas necessária - O Brasil quer ampliar produção de energia nuclear para fins civis, e entrar no mercado mundial de urânio enriquecido. Desafios do Desenvolvimento. Brasília: Ipea, 2010. Disponível em: <http:// desafios.ipea.gov.br/index.php?option=com_content\&view=article\&id=1296:reportag ens-materias\&Itemid=39>. Acesso em: 20 maio 2015 .

GFP - GLOBAL FIREPOWER. Total Submarine Strength by Country. Disponível em: <http://fas.org/issues/nuclear-weapons/status-world-nuclear-forces/>. Acesso em: 22 maio 2015.

GUIMARÃES, S. P. Desafios brasileiros na era dos gigantes. Rio de Janeiro: Contraponto, 2005.

KAYE, Y. US officials: 'Saudis set to buy nuclear weapons from Pakistan'. International Business Times. 17 de maio de 2015. Disponível em: <http://www.ibtimes.co.uk/ us-officials-saudis-set-buy-nuclear-weapons-pakistan-1501733>. Acessado em: 19 maio 2015.

LANGMUIR, I. Uma corrida armamentista atômica e suas alternativas. In . Um mundo ou nenhum: Relatório ao público sobre o pleno significado da bomba atômica. São Paulo: Paz e Terra, 2008.

LEITÃO, S. Energia: um debate vital para o país. Estudos Avançados, São Paulo, v.27, n.77, p.207-216, abril 2013.

LENZI, C. L. Sociologia ambiental: risco e sustentabilidade da modernidade. Bauru: Edusc, 2006.

MECKLIN, J. Disarm and Modernize, Foreign Policy. Março/Abril, 2015. 
NORRIS, R. S.; KRISTENSEN, H. M. Global nuclear weapons inventory, 19452010. Bulleting of the Atomic Scientists. Junho/Agosto 2010. Disponível em: <http://thebulletin.org/2010/julyaugust/global-nuclear-weapons-inventories-1945\%E2\%80\%932010>. Acesso em: 23 mai. 2015.

PESSOA, M. Leis da guerra e armas nucleares. Rio de Janeiro: Revista dos Tribunais, 1969.

SIPRI - STOCKHOLM INTERNATIONAL PEACE RESEARCH INSTITUTE. Nuclear forces reduced while modernizations continue, says SIPRI. SIPRI, 16 de maio de 2014. Disponível em: <http://www.sipri.org/media/pressreleases/2014/nuclear_May_2014>. Acesso em: 21 maio 2015.

SWENSON-WRIGHT, J. What lies behind North Korea's nuclear claims. 20 de maio de 2015. Disponível em: <http://www.bbc.com/news/world-asia-32817524>. Acesso em: 22 maio 2015.

THE EXPRESS TRIBUNE. Pakistan surspasses India's nuke count: Report. 10 de março de 2015. Disponível em: <http://tribune.com.pk/story/850805/pakistan-has-more-nukes-than-india-now-report/>. Acessado em: 22 maio 2015.

URBAN, M. Saudi nuclear weapons 'on order' from Pakistan. BBC News. 6 de novembro de 2015. Disponível em: <http://www.bbc.com/news/world-middle-east-24823846>. Acesso em: 15 maio 2015.

U.S. DEPARTMENT OF STATE (a). Article by Article Legal Analysis of the START Treaty and its Associated Documents (Part 1). Disponível em: <http://www.state. gov/t/avc/trty/104056.htm>. Acesso em: 21 maio 2015.

U.S. DEPARTMENT OF STATE (b). New START Treaty. Disponível em: <http:// www.state.gov/t/avc/newstart/>. Acesso em: 22 maio 2015.

YALE LAW SHOOL. The Atomic Bombings of Hiroshima and Nagasaki: Chapter $10-$ Total Casualties. The Avalon Project, 2008. Disponível em: <http://avalon.law.yale. edu/20th_century/mp09.asp>. Acesso em: 19 maio 2015.

RESUMO: Neste artigo analiso se a tragédia das explosões nucleares em Hiroshima e Nagasaki ensinou algo de definitivo à humanidade, demonstrando o poder fatal das armas nucleares, o que continuaria a justificar o seu banimento da face da Terra. E o faço debatendo em que medida as discussões sobre o poder atômico repercutiram no Brasil, apontando as similaridades entre os argumentos utilizados nos idos dos anos 1970 e no momento atual, quando setores do país argumentam que não podemos prescindir do poderio atômico para assegurar nossa devida relevância no cenário político internacional.

PALAVRAS-CHAVE: Poderio atômico, Armas de saturação, Controle das armas nucleares, Desarmamento, Equilíbrio de poder, Soberania, Comunidade de perigo, Hibakusha, Usinas nucleares, Tratado de não proliferação de armas nucleares.

ABSTRACT - In this article, I analyze whether the tragedy of the nuclear explosions in Hiroshima and Nagasaki taught humanity anything definitive, having demonstrated the fatal power of nuclear weapons, thereby justifying their continued ban on Earth. To 
this end, I discuss to what extent debates on atomic power have had repercussions in Brazil, pointing out the similarities between the arguments used in the bygone 1970s and in the present moment, when certain sectors of the country are contending that in order to ensure our due role in the international political scene we cannot do without atomic power.

KEYWORDS: Atomic power; Saturation weapons; Control of nuclear weapons; Disarmament; Balance of power; Sovereignty; Community in risk; Hibakusha; Nuclear power plants; Treaty on the non-proliferation of nuclear weapons.

Sergio Leitão é advogado, diretor de Políticas Públicas do Greenpeace no Brasil de 2005 até 2015. É fundador e diretor do Instituto Escolhas. @ - sergio.leitao@greenpeace.org Colaborador de pesquisa: Thiago Almeida

Recebido em 29.5.2015 e aceito em 22.6.2015.

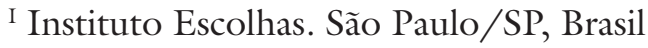

